\title{
Entdecken Sie uns online
}

_ Wenn ich jemandem etwas schenke, überlege ich mir immer sehr genau, was zu ihm passen könnte. Nicht immer klappt das, doch lande ich einen Treffer, freue ich mich. Ähnlich erging es mir, als eine Leserin bei mir anrief und fragte, ob sie die Bilder des Artikels „Eigenübungen für das Kiefergelenk“ aus physiopraxis 2/12 haben könne. Sie wolle damit ein Übungsblatt für ihre Patienten zusammenstellen. Diese Mühe müsse sie sich nicht machen, meinte ich, und verwies sie auf das Übungsblatt für Patienten zum Herunterladen und Ausdrucken im Online-Artikelarchiv der physiopraxis. Das fand sie prima.

_ Kürzlich kam eine Kollegin von einem Praxisbesuch zurück und berichtete, die Inha-

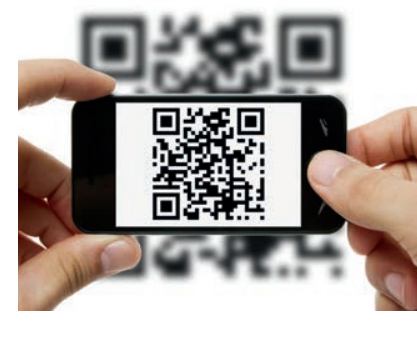
berin und ihr Team seien von physiopraxis ganz begeistert. Sie nutzen Artikel für interne Fortbildungen - vor allem die Rubrik Hands-on/Hands-off. Ein Leser schrieb, er finde die ergänzenden Videos praktisch, um den Patienten die Übung auf dem iPhone zu zeigen oder selbst die Handgriffe zu üben. Das freut uns, zeigt es uns doch, wir sind auf dem richtigen Weg und unsere Online-Angebote kommen an.

_ Wir wollen unseren Lesern möglichst viel Service bieten und es ihnen einfach machen. Deshalb tragen die Infokästen, die auf die zusätzlichen Materialien hinweisen, künftig einen physiopraxis-plus-Button, zu sehen auch auf Seite $45 \mathrm{im}$ Artikel „Messbein für lymphologische Kompressionsbandagierung“. Ein Video stellt das Messbein vor, ein zweites, wie die Kompressionsbandagierung richtig erfolgt. Immer wenn Sie den blau-grünen Button sehen, wissen Sie: Jetzt warten auf Sie Übungsblätter oder Videos unter www.thieme-connect.de/ejournals/ physiopraxis, um heruntergeladen zu werden.

Herzlich, Ihre
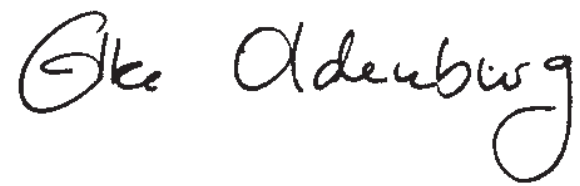

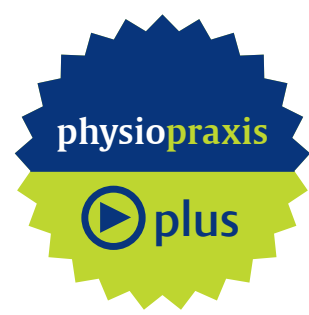

QR-Codes machen das Leben leichter. Scannen Sie diese ab, können Sie auf dem iPhone auch unterwegs Videos anschauen. 